Georgia State University

ScholarWorks @ Georgia State University

\title{
Criminal Group Dynamics and Network Methods
}

\author{
Marie Ouellet \\ Georgia State University, mouellet@gsu.edu \\ Sadaf Hashimi \\ Rutgers University - Newark, sadaf.hashimi@rutgers.edu
}

Follow this and additional works at: https://scholarworks.gsu.edu/cj_facpub

Part of the Criminology and Criminal Justice Commons

\section{Recommended Citation}

Ouellet, Marie, and Sadaf Hashimi. 2019. Criminal Group Dynamics and Network Methods. Deflem, M. and Silva, D. (Ed.) Methods of Criminology and Criminal Justice Research (Sociology of Crime, Law and Deviance, Vol. 24), Emerald Publishing Limited, pp. 47-65.

This Book Chapter is brought to you for free and open access by the Department of Criminal Justice and Criminology at ScholarWorks @ Georgia State University. It has been accepted for inclusion in CJC Publications by an authorized administrator of ScholarWorks @ Georgia State University. For more information, please contact scholarworks@gsu.edu. 
CRIMINAL GROUP DYNAMICS AND NETWORK METHODS

\author{
Marie Ouellet* \\ Georgia State University \\ Sadaf Hashimi \\ Rutgers University
}

*Address correspondence to Marie Ouellet at mouellet@gsu.edu 


\title{
CRIMINAL GROUP DYNAMICS AND NETWORK METHODS
}

\begin{abstract}
Purpose - Criminal groups have long been central to explanations of crime and deviance. Yet, challenges in measuring their dynamic and transient nature meant group-level explanations were often displaced in favor of individual-level ones. This chapter outlines how network methods provide a powerful tool for modeling the dynamic nature of criminal groups and other social systems.
\end{abstract}

Approach - We start by providing a brief introduction to social network analysis, including key concepts and terminology. We then focus on the types of relational data available to study criminal groups, and how network methods can be used to delineate group boundaries. We conclude by presenting a framework for understanding group dynamics from a network perspective, describing the contributions of network analysis to theories of group processes.

Findings - Network methods have provided meaningful advances to the study of group dynamics, forcing us to revisit assumptions about the impact of a group's structure on delinquent behavior. Network studies of group dynamics have primarily focused on the cohesion-delinquency link (within-group structure) and the social contagion of conflict (between-group structure), highlighting important opportunities for the intersection of these two inquiries.

Value - Network methods provide a means to revisit and extend theories of crime and delinquency with a focus on social relations and structure. The unique affinity between group dynamics and network methods highlights immense opportunities for expanding our knowledge of collective trajectories.

Keywords: Network methods, group dynamics, relational data, group boundaries, delinquency 


\section{INTRODUCTION}

The wide array of criminal groups has been well documented by decades of research (e.g., Klein, 1971; Miller, 2001; Thrasher, 1927). There are groups that seize to exist beyond a single crime incident, and others that survive for decades. There are groups that engage in versatile offending repertoires, and those that develop specialized profiles. There are groups that engage in episodic delinquent activity, and those for which delinquency is a staple of their existence.

These variations, however, create difficulties for defining, delimiting and measuring criminal groups. Indeed, early explanations of criminal group processes often relied on extensive field research, spanning years of observations of members and their interactions. This research yielded important insights about group processes and delinquency, including the role of a group's structural features in shaping group processes. This idea was the basic premise of Short and Strodtbeck's (1965) seminal piece on Chicago gangs. They observed that delinquent behavior was directly related to social processes that emerged in the day-today of gang members lives, including their interactions with one another and with other groups. Similarly, Block's (1979) work on organized crime in mid-century New York City showed that criminal syndicates operated in 'alliance networks' that structured groups' abilities to maximize profits and evade sanctions. However, despite many decades of research, group-level studies have been primarily descriptive in nature, creating important gaps in explanatory accounts of group dynamics.

The gaps in our knowledge are, in part, due to a lack of group-level data. Although group dynamics were once central to explanations of crime, advances in survey research during the 1970's shifted individual-based research to the forefront of criminology (e.g., Bursik, 1998; Kreager et al., 2011). The shift was not undue. It allowed for important methodological and theoretical developments, including the ability to generate representative samples, a major critique of early field research on criminal groups. However, it virtually displaced group-level explanations of crime - a phenomenon that was observed across the study of gangs (Pyrooz \& Mitchell, 2015), criminal enterprises (Paoli, 2002), delinquent peer groups (Kreager et al., 2011), and terrorist organizations (Miller, 2012).

This chapter aims to outline how a network framework can be leveraged to address these gaps in our knowledge and foster explanatory research. Network methods are uniquely suited to measure the dynamic and transient nature of groups, mapping out social relations, delineating group structure, and allowing for cross-comparisons across groups. Network 
methods have led to meaningful advances in the structure of criminal operations ${ }^{1}$; however, a large proportion of these studies focus primarily on understanding the role networks play in shaping individual behavior (Carrington, 2011). This chapter aims to foster group-level research, by demonstrating how network methods can be used to move up the analytical ladder, to examine variation in collective trajectories.

In this chapter, we start by providing a brief introduction to a network perspective, including key terminology and concepts. We then outline the various relational data sources that scholars have relied on to study group dynamics, and how network methods provide a set of methodological techniques for delineating group boundaries. Next, we present a framework for examining group dynamics, distinguishing between studies that focus on within-group and between-group social structures. We conclude by highlighting how these two areas intersect, and opportunities for moving the field forward.

\section{A NETWORK PERSPECTIVE OF DELINQUENT GROUPS}

A network perspective views social units within a system as interdependent, and these dependencies as key for explaining the emergence and evolution of behavior. This perspective has a clear affinity with group dynamics, which has defined the essence of a group not in "the similarity or dissimilarity of its members, but their interdependence" (Lewin, 1948, p. 84), viewing groups as dynamic wholes, whereby collective identities are shaped and prescribed by interactions between group members. Indeed, a large body of research has demonstrated the importance of social relations for shaping a group's trajectory, including the ability to spread behaviors, increase compliance, and regenerate over time.

Networks refer to the mathematical representations of the relationships that link different units within a system. These units - referred to as vertices - may represent entities across different levels of analysis, including individuals (e.g., gang members, youth), groups (e.g., gangs, peer groups), or larger collectives (e.g., gang task forces). The links - referred to as edges - represent relationships between the vertices. Edges may be operationalized as binary links - the presence or absence of a relationship (however defined) or can be built up to further characterize the relationship. For instance, edges may be directed, representing the flow of information or resources (e.g., A phones B, but B never phones A); valued, indicating the intensity or frequency of interaction (e.g., the number of times A phones B), and/or multiplex, representing the presence of multiple relationship-types (e.g., A and B are both part of the same gang and siblings). Network methods provide a set of tools to identify and describe the structural properties of these networks, as well as a set of models and techniques 
to examine the sources and patterns of interactions in social relationships (Carrington, Scott, \& Wasserman, 2005).

The application of network methods to the study of delinquent groups requires distinguishing between complete-network data and ego-network data. Studies of criminal groups require complete-network data when the unit of analysis are individuals (e.g., gang members), providing a complete representation of all the actors and their links within the social system. Network analysis can then be used to assess the structural properties of a group, including the degree to which it is structured as a cohesive entity or is centralized around a subset of highly connected members. In contrast, when the unit of analysis are groups (e.g., gangs), studies of criminal groups may rely on either complete-network data, the full set of relationships between all groups, or ego-network data, capturing the 'local' connections around any one group. Maps of the relationships between groups can be used to examine larger network structure, including the degree to which a group is embedded in a network of alliances and/or rivalries, and how interdependence between these groups influences social processes.

\section{NETWORK DATA}

Network methods depend on obtaining valid and reliable data. Studies relying on network methods to examine criminal group dynamics have acquired network data from various sources, including: 1) field observations, 2) police records, 3) archived materials, 4) selfreports and 5) online data. Ideally, network data should reflect the full population of interest; however, who to include or exclude is often restricted by practical constraints - "who is in the data' rather than theoretical questions 'who should be considered part of the network'. While some data sources may be more reliable, they may be less relevant or accessible, and conversely, while some data sources are relevant, they may be less reliable or representative. Below we detail how scholars have leveraged these sources to understand group dynamics, and what they can, and cannot tell us about group network structure.

Some of the earliest applications of network analysis to criminal groups drew from field observations of gang members. For instance, the Boston Special Youth Project founded in the 1950s by Water J. Miller, a federally funded study of juvenile delinquency in Roxbury, MA, relied heavily on detached workers and their interactions with gangs and gang members to obtain relational data. Specifically, contact cards maintained by the workers detailing the nature of their interactions with gang members (e.g., name, date, location, group), the author's interactions with outreach workers, as well as the author's personal interactions with 
gang members, and group meetings were used to address gang delinquency and restructure the activities of adolescence street gangs (see Miller, 1957; 1958; 1962). More recently, scholars have revisited the detailed field notes of early gang scholars to reconstruct the social structure of gangs and their members. Papachristos (2006) mapped the social network of a Chicago gang using Suttles's (1968) recorded observations of their social interactions. Relational data collected from field observations provide a valuable source of network data, affording in-depth coverage of the set and types of relationships between actors. However, data collection is labor-intensive and thus is often restricted to a subset of groups, often those that are more readily accessible, creating concerns about the representativity of results.

More recent research has leveraged relational data present in police records, including arrest and field incident reports. Arrest records afford information on two types of ties: i) cooffending, cases where more than one individual has been arrested for the same criminal incident, and ii) offender-victim relationships, cases where the crime incident records both an alleged perpetrator(s), and the alleged victim(s). Thus, arrest records provide information on individuals who collaborate (i.e., co-offend together), and individuals who are in conflict (i.e., offender-victimization links). In contrast, field incident records provide information on non-criminal ties, cases where officers document the individuals they encounter in their daily routines (e.g., Hashimi \& Bouchard, 2017). These non-criminal ties may overlap with criminal-ties found in arrest records, or present distinct relationships not previously recorded. Police records thus provide a two-mode data structure (ties to incidents), where individuals are linked based on their joint involvement in the same incident or behavior. Researchers can then rely on a one-mode projection (ties between individuals) of these incidents, connecting individuals through their co-involvement in the same event. Police records have been increasingly used to understand group dynamics to delineate the scope of organized crime groups (e.g., Hashimi et al., 2017), examine trends in group crime (e.g., Carrington, 2002; Lantz \& Hutchison, 2015; Sarnecki, 2001), and conflict between groups (e.g., Papachristos, 2009).

Police records are impressive in their scope, creating networks of co-offenders and co-associates, on a scale that may not otherwise be available. But the breadth of the data comes at a cost to its depth and representativity. Official records are limited to the individuals for which there was available evidence, were present at the crime incident, and who were detected by police, thus imposing boundaries on groups that may be much more fluid and dynamic than they seem. Similarly, discrepancies in how agencies record and define crime incidents, departmental mandates, and variation in resources, means that some individuals 
(and their interactions) are more likely to be detected than others. Further, police records only tell us about behavioral ties, instances where individuals were observed (or alleged) to be engaging in the same type of behavior together. Thus, these networks only provide a subset of an individual's larger network. As such, it limits our considerations of individuals beyond those involved in the behavior and the larger group structure from which the behavior emerged.

Archived records, including court files, meeting minutes, and public inquiries, have also formed the foundation of many network studies. The sources of archived records are extensive. For instance, Crossley et al. (2012) relied on the UK Home Office files, which detailed all individuals who were in court for suffragette-related incidents from 1906 to 1914, allowing them to extract 'co-offending' links between suffragettes who appeared in court together for the same incident. Others have relied on archived electronic surveillance records of illicit organizations, such as wiretaps, to map out the networks of their operations (e.g., Campana, 2011; Malm, Bichler, \& Nash, 2011; Morselli, 2009). Electronic wiretaps provide valuable information on both the network of phone calls, but also the content of these phone calls, which allows researchers to understand the context of the relationships between callers for more reliable interpretations (Campana, 2015; Campana \& Varese, 2012). In another innovative study, Baker and Faulkner (1993) mapped out the social organization of a pricefixing conspiracy by relying on testimony and meeting minutes made available from a public inquiry into the organization. Similar to police sources, archived records provide valuable information, but are restricted to the individuals and interactions detected and then recorded into files.

Self-report data collected from surveys and interviews provide a valuable resource for researchers wanting to surmount limitations in official and archived sources. Surveys and interviews may be marshaled to collect network data by asking respondents to nominate or select their peers according to a pre-defined criterion. For instance, the National Longitudinal Study of Adolescent to Adult Health (Add Health) in-school questionnaire was administered to 90,118 students enrolled in 145 schools across 80 communities. Students were asked to nominate up to five male and five female friends from all students enrolled in the respondent's school or their sister school (Harris et al., 2009). Importantly in 16 of the schools (i.e., the 'saturation' sample), all students were solicited to participate in the survey. For this sub-sample, the complete network of friendships within a high school may be analyzed, by linking student nominations (see Gallupe \& Gravel, 2018). 
Surveys provide researchers with the flexibility to specify the number, type, and characterization of relationships. The greater control researchers have over the data collection procedure is a major strength of this approach, especially when compared to police or archived records. Survey data of complete networks - where all members within a bounded population have been sampled - has been used to study the social structure of peer friendship groups (Kreager et al., 2011), gang networks (Hughes, 2013), and inmate groups (Schaefer et al., 2017). However, the use of survey data to study criminal groups is limited to the degree that all members of a bounded population can be sampled. Bounded populations may be more clearly defined in some samples, such as high school students, but more ambiguous in others, such as gangs where fluid boundaries preclude the existence of a roster of all members of a group, or even be known to all members.

Further, network studies may rely on data collection tools already in the criminologist repertoire, such as snowball sampling of hidden populations (e.g., Decker, 1996). An extension of this technique, respondent-driven sampling, relies on patterns in repeated waves of recruitment to make statistical inferences about the full population under study, and help infer group boundaries (e.g., Heckathorn, 1997; Heckathorn \& Cameron, 2017). In addition, the rise in social media provides additional sources for extending the pool of available data, by reaching populations that would be too difficult to study with traditional methods. Social media has already proven to be a valuable source to understand group dynamics with social networking platforms like Twitter (e.g., Patton et al., 2017), and Facebook (e.g., Lane, 2019), along with email records (e.g., Palla Barabási, \& Vicsek, 2007) mobile phone data (e.g., Eagle, Pentland \& Lazer, 2009; Morselli, 2009; Sugie, 2018) and other electronic tools such as the Global Positioning System (Schmidt, 2012), tracking and recording information on the ways in which groups interact and organize themselves in the "online" versus "offline" world. With this source comes an unprecedented opportunity to adopt an interdisciplinary approach and employ machine learning and computational techniques to mine network data. The impact of media communication and its capability to reach others by decreasing both social and spatial distance allows individuals to establish new forms of social ties and creates new forms of group organization (Castells, 2000).

The selection of a data source is the fundamental building block to designing reliable and valid network studies, as it guides who will and will not be included in the network, along with the types of relationships to be considered. The various data collection strategies are not mutually exclusive, and there is ample evidence of scholars merging multiple sources (e.g., Malm et al., 2011; Stevenson \& Crossley, 2011). However, more work on the validity 
of network data is required. Each data source has known limitations, yet little is known about how inferences about group dynamics range across these data sources. Some work has been done to examine the validity of structural inferences across official records and self-reports (e.g., Ouellet \& Bouchard, 2018; Sarnecki, 2001); however, these have focused on case studies, and more systematic efforts on the precise measurement biases, including how network data converges (or diverges) across sources is needed.

Additionally, an often-overlooked step is the time coverage of the data source. Social networks are dynamic; ties form, grow stronger and weaker, and eventually dissolve, with change being dependent on the characteristics of those that make up the network along with the structure of the network itself. As such, periods on which group-level data are sampled is essential. Data aggregated across extended periods may misconstrue the true group structure at any one-time point. Klein and Crawford (1967) highlighted this point when discussing the scope of gangs, finding that some numbered over a few hundred when data were aggregated across multiple time points, but in reality, only consisted of 30 to 40 members at any single point in time. This is particularly important for network studies, where many metrics depend on the number of actors. Just like inaccuracies in network data can lead to fundamentally different representations of the same group, so can different observation periods.

\section{A NETWORK APPROACH TO DELINEATING GROUP BOUNDARIES}

The available relational data provides cues for researchers looking to design network-based studies of criminal groups. However, relational data may provide information on the relationships between individuals in the dataset, but not on group boundaries. We may know, for instance, the full set of interactions between students in a school, inmates in a prison, or offenders in a police district, but not much about the social groups these actors belong to. Network methods provide a unique approach to resolving this issue, offering a set of methodological techniques to partition network data into groups according to patterns of social relations. Techniques such as block modeling, hierarchical clustering, and community detection have largely been applied by scholars grounded in computer science, physics, and related fields, as well as the biological and social sciences.

Criminology scholars have primarily relied on community detection techniques to delineate groups from relational data. The overall aim of community detection is to extract subgroups from the larger network that correspond with meaningful conceptualizations of social groups. Theoretically, community detection draws on suggestions by early scholars, such as Simmel (1955) who emphasized that while individuals are embedded in various webs 
of affiliations, strong(er) social ties are more likely to form with those who are in one's immediate vicinity; their local "circle" as opposed to their larger social environment. It is through these immediate, local ties that larger heterogeneous networks of individuals filter into smaller homogenous groups. Methodologically, community detection aims to quantify the "intuitive concept of community structure" by arranging edges (ties between actors) into groups (Newman, 2006, p. 8578) - thus, identifying areas of structural homogeneity within the larger heterogeneous network graph. Community detection methods can be broadly divided into two classes of techniques: modularity- and clique-based approaches.

Modularity-based approaches partition network graphs into densely connected subgroups with loose connections between groups. This approach takes into account both the proportion of within-group edges (high within-group connectivity) and between-group edges (low between-group connectivity) (e.g., Girvan \& Newman, 2002; Newman \& Girvan, 2004). The degree to which a network graph can be partitioned into subgraphs is assessed via a modularity score, which represents a weighted function of within- as compared to betweengroup ties. The modularity score ranges from 0 to 1 , with scores closer to 1 representing a better fit, and a perfect score of 1, cases where all ties exist within the group and zero ties between groups. There are multiple modularity-maximization techniques; some of the most popular include the Girvan-Newman (Girvan \& Newman, 2002); Newman (Clauset, Newman, \& Moore, 2004), and Louvain (Blondel et al., 2008). The selection of the appropriate method often depends on the solution with the highest modularity score and greatest face validity, as compared to other solutions.

Modularity-based techniques provide a flexible approach to detect group boundaries; they can be used for weighted, directed, and longitudinal graphs (e.g., Mucha et al., 2010). Kreager et al. (2011) demonstrated the utility of a modularity-based approach to discern peer friendship groups across students in 27 Iowan and Pennsylvania high schools. Relying on the complete network of friendship nominations across 9,385 ninth-grade students, the authors delineated 897 distinct peer groups. These groups formed the unit of analysis for the study, which examined the link between a group's delinquency and structural features. Scholars have since applied modularity-based approaches to extract groups of co-offenders (e.g., Lantz \& Hutchison, 2015; Ouellet et al., 2019); gangs (e.g., van Gennip et al., 2012), inmates (e.g., Schaefer et al., 2017), criminal organizations (e.g., Calderoni, Brunetto, \& Picardi, 2017), and cryptomarket vendors (e.g., Duxbury \& Haynie, 2018). Though widely used, modularitybased approaches have been critiqued for being limited in nature and scope. Methodologically, modularity-based techniques have been found to suffer from degeneracy, 
where a high number of alternative high scoring partitions may be extracted from the full network graph (Good, de Montjoye, \& Clauset, 2010), and resolution limits, where subgroups are unable to be detected if they are too small relative to the overall size of the network (Fortunato \& Barthélemy, 2007). Theoretically, modularity-based techniques have been critiqued for limiting membership to a single group, with scholars emphasizing that this imposes "an artificial constraint on the groupings they are seeking to uncover" (Everett \& Borgatti, 1998, p. 49).

Clique-based approaches distinguish themselves from modularity-based techniques primarily by their ability to produce overlapping groups, where group membership is not mutually exclusive. Cliques represent the most fundamental notion of a subgroup where each actor is connected to every other actor, with triads - a set of three actors who are all connected - the simplest notion of a clique. The clique percolation method (CPM) is one of the first clique-based techniques to detect subgroups from relational data (Palla et al., 2005). The CPM works by first identifying all cliques of size $k$ in a network graph. It then generates a new graph where each vertex represents one of the $k$-cliques. Vertices (i.e., $k$-cliques) are then clustered into larger groups if they are adjacent to other vertices, where adjacency is defined by any $k$-cliques that share $k$ - 1 members. Because an actor can belong to more than one $k$-clique, these groups can overlap.

In contrast to modularity-based approaches, the number of optimal groups is selected by the researcher who determines the size of the initial $k$-clique. Consequently, individuals may be excluded from any grouping as not all individuals in a network graph may belong to a clique of size $k$. As such, solutions of $k$-size should aim to maximize coverage of the actors within the graph (Palla et al., 2005). Although CPM offers clear advantages for delineating group boundaries, it is not without its limits, having been shown to perform poorly in network graphs with few cliques (see Newman, 2018).

Schaefer et al. (2017) applied the CPM to delineate subgroups of inmates in a medium-security prison. Relying on 'get-along' nominations, the authors uncovered 12 social groups among the inmates. Representing one of the few studies to compare modularity and clique-based social groupings, the authors showed that modularity-based approaches identified eight groups. Rather than pit the two approaches, the authors demonstrated how they offered complementary information on the social organization of prisons and reinforced the finding that inmates were organized into racial and religious heterogeneous social groups. However, the study also highlighted how the two approaches created important differences in the distribution of groups, with the modularity-based groups ranging from 8 to 26 members, 
and the clique-based groups uncovering one larger social grouping of 61 inmates, and many smaller ones.

Important methodological advances have been made to delineate group boundaries from relational data, including the ability to account for the frequency and duration of interactions, as well as more advanced methods such as the mixed-membership stochastic block model (Airoldi et al., 2008). One of the rare examples to validate groups extracted using these techniques includes van Gennip et al.'s (2012) validation of algorithmically detected communities extracted from the networks of individuals as recorded in field incident cards by the Los Angeles Police Department with law enforcement's knowledge of gangs. But more efforts should be made to validate community partitions, particularly with selfreports of group members. Studies may also rely on methodological approaches to validate the extracted partitions, such as similarity and dissimilarity measures that can be used to assess the effect of different distance measures on the quality of community detection algorithm results (Shirkhorshidi, Aghabozorgi, \& Wah, 2015).

\section{RESEARCH ON CRIMINAL GROUP DYNAMICS}

Studies equipped with criminal network data are uniquely positioned to revisit and extend theories of crime and delinquency. Early applications of network analysis provided descriptive accounts of the social structure of criminal groups, challenging dominant perspectives that gangs and other criminal entities were hierarchically structured organizations (e.g., McGloin, 2005; Morselli, 2009), while also examining the sources of this structure (e.g., Bright, Koskinen, \& Malm, 2018; Crossley et al., 2012; Morselli, Giguère, \& Petit, 2007), and its impact on individual trajectories (e.g., Haynie, 2001; McGloin \& Piquero, 2010; Morselli \& Tremblay, 2004; Morselli et al., 2006). The underlying premise of these studies was that the etiology of crime was inherently a social phenomenon that shaped the emergence and evolution of delinquent activity. More recent studies have aimed to test these premises on collective trajectories, by providing explanatory accounts of how group dynamics influence behavior. These studies can be broadly categorized into two classes: studies that examine intra-group dynamics (within-group structure), and studies that examine inter-group dynamics (between-group structure).

\section{Intra-Group Network Dynamics}

Intra-group explanations make use of within-group interactions to account for group behavior. Much of this work has focused on the internal connectivity - or cohesiveness - of a 
group. Cohesion has long been central to theorizing about criminal group processes, often viewed as a key governing force of group behavior, influencing patterns in group delinquency and violence (e.g., Decker, 1996; Jansyn, 1966; Short \& Strodtbeck, 1965; Vigil, 1988). Conceptually, cohesion refers to the degree of solidarity and unity between members within a group (e.g., Collins, 1988; Decker \& Curry, 2002). However, challenges in directly measuring cohesion has meant that many theories of cohesion have remained largely untested (see Papachristos, 2013). Network methods have aimed to fill this gap by providing a set of measures to quantify group cohesion, based on patterns in members' social interactions, and the degree to which groups are structured into tightly knit entities.

A classic study of gangs made direct connections between a group's cohesion and delinquency. Its key concept - cohesion - was defined as the "mutual liking or acceptance, attraction to group, degree of shared norms or values, and resistance to disruptive forces" (Klein \& Crawford, 1967 p. 69). However, the authors rejected traditional approaches to operationalizing cohesion in favor of a network approach that directly measured member interactions. Relying on detached worker contact cards, which recorded workers' daily observations of gang members and who they were seen with, the authors mapped out the interactions between 576 gang members across four gang clusters. The cohesiveness of each gang cluster was operationalized as the degree to which members formed tightly connected groups, according to nine different network indices, including a measure of the overall density of the group (i.e., the number of connections between gang members as a proportion of all possible connections). Comparing a group's cohesiveness with their delinquency, the authors found a positive association between cohesiveness and delinquency, with the most cohesive groups being the most delinquent.

Despite the important contribution of network methods to operationalize cohesion, it would be nearly half a century before scholars would re-test the cohesion-delinquency link with statistical models across samples of delinquent and non-delinquent groups. Kreager et al. (2011) examined the sources of a group's cohesion across 897 peer friendship groups with varying levels of delinquency. Cohesion was measured as a group's: transitivity (degree to which groups consisted of triads), reciprocity (the percent of friendship nominations within a group that were reciprocated), and structural cohesion (the mean number of node independent paths). However, in contrast to Klein and Crawford (1967), the findings did not support a consistent relationship between a group's cohesiveness and delinquency. Once behavioral and attitudinal measures were controlled for, only transitivity was found to be positively associated with a group's overall delinquency. A null relationship between a group's 
delinquency and cohesion was also supported by Hughes (2013) study of Chicago gangs. Resurrecting relational data embedded in surveys of 248 gang members conducted during Short and Strodtbeck's (1965) field research in Chicago, she examined variation in delinquency and cohesion across 11 gangs. Measuring cohesion as the average number of friends nominated by each gang member within the gang, results showed that a group's cohesion did not predict its general delinquency levels, but it did negatively predict a group's violence. $^{2}$

Network approaches have provided meaningful advances in unpacking the cohesiondelinquency relationship - allowing us to look at cohesion across large samples of delinquent and non-delinquent groups and forcing us to revisit assumptions about the impact of a group's structure on collective behavior. However, the relationship between a group's cohesion and delinquency is far from conclusive, lacking replication and longitudinal studies. One way forward would be to extend these examinations to focus on the temporal order of the cohesion-delinquency relationship. Scholars working on cohesion and delinquency typically focus on one strategy and point the causal arrow in a single direction. However, the direction of the relationship is unclear. Cohesion ebbs and flows across a group's life cycle, and the relationship with delinquency may not be linear, but rather reflect dynamic, reciprocal, or cumulative processes. For some, it is less cohesive groups that are more likely to engage in delinquent acts to bring together members (e.g., Jansyn, 1966). For others it is the more cohesive groups that are more likely to engage in delinquency, embedded in tightly knit structures that facilitate the transfer of norms (e.g., Klein, 1969; Thornberry et al., 1993). As part of this research agenda, it would also be meaningful to investigate whether sources of cohesion change across a group's evolution. It may be that cohesion is important when the group is still forming, but its effect dwindles as group activities shift or exhibit greater mobility.

Efforts to look at the flow of cohesion over time may draw from research in the social movement literature, which has conducted detailed accounts of a group's evolution over time. For instance, focusing on a case study of the Provisional Irish Republican Army, Stevenson, and Crossley (2014) demonstrated that despite high turnover the group remained structurally stable. The group maintained a core set of members who became more central over time and connected the group as it evolved. This study suggests that subgroups within the criminal group were just as important as the overall structure of the group itself. 
Groups, delinquent or otherwise, are rarely isolated entities but are rather embedded in a web of relations. Decades of research have shown that neighboring groups play important roles in shaping a group's own identity and behavior, influencing groups' identities, serving as reference points, and structruing the spread of behaviors (e.g., Decker, 1996; Decker \& Curry, 2002; Klein, 1971; Sanchez-Jankowski, 1991; Thrasher, 1927). Although these studies did not explicitly rely on formal network methods or terminology, their early insights into inter-group social processes shaped the network agenda. Network scholars have since mapped out the networks of collaboration and conflict between groups as a means to explicitly test these early perspectives and their implications for group behavior.

In a study of Chicago gangs, Papachristos (2009) provided one of the most influential demonstrations of the relevance of network methods for understanding the spread of gang violence. Defining gang conflict, as "first and foremost an interaction" (p. 75) he mapped out the network of conflict between all gangs who had been involved in a homicide, either as a perpetrator or a victim, for nearly two decades of violent conflict in Chicago. The data, extracted from law enforcement records, provided the full network of lethal rivalries between gangs. From this network, Papachristos (2009) estimated the likelihood that any two gangs would engage in lethal conflict with one another based on previous patterns of conflict. The results highlighted a social contagion process, whereby the likelihood of violence was governed by cycles of reciprocal murders - cases where gangs were more likely to target gangs that they had targeted or had been targeted by in the past - creating institutionalized patterns of violence (p. 118).

Extending this research, Papachristos et al. (2013) tested claims that violence served as a means for gangs to assert their social standing, creating the presence of dominance hierarchies. Specifically, he drew from a body of literature that observed the consequences of dominance hierarchies through interchanges of aggression. Chase (1980) illustrated the concept of dominance hierarchies by observing aggression in chickens. He found that a chicken that wins in a pecking contest involving two other chickens (e.g., a symbol of dominance), is less likely to be a victim of future attacks. The losing chicken, however, may become a victim of future attacks, being perceived as a vulnerable subordinate by others, or can adopt a more aggressive stance against a less dominant chicken, rising to the middle of the pecking order. Drawing analogies with the gang dominance literature, Papachristos et al. (2013) tested whether gang members that successfully use violence to settle disputes, or retaliate, were less likely to become victims as they have asserted their dominance. And 
whether the converse was equally true, where a failure to react to violence is detrimental to the reputation of the gangs as others within the network will interpret their lack of action as a weakness, making the gang and its members susceptible to future aggressors (Gould, 2003, p. 118; Papachristos, 2009). The main construct - dominance hierarchies - was measured as a network variable, whereby more aggressive gangs (more out-group ties) were presumed to have a higher status than victimized gangs (more in-group ties). Specifically, a transitive triad term allowed them to test for whether gangs exhibited different status rankings according to their violence profiles. ${ }^{3}$ Findings from exponential random graph models showed that dominance hierarchies were not associated with gang conflict; rather, results bolstered earlier findings: lethal violence between gangs was primarily a function of reciprocal violence, where gangs were more likely to engage in conflict if a member of their gang had previously been targeted. Yet, the authors suggested the lack of relationship may have been due to an alliance structure that they were unable to observe.

Since Papachristos's (2009) seminal study, scores of research findings have affirmed that gang violence spreads through a social contagion process in Boston (Papachristos et al., 2013); Chicago (Papachristos, 2009; Papachristos et al., 2013), and Los Angeles (Radil, Flint, \& Tita, 2010; Tita \& Radil, 2011). These studies provide important insights, and shed light on ways forward. For instance, studies of violence have primarily focused on the role of 'conflict' ties rather than 'collaborative' ties between gangs. We know from earlier studies that network rivalries are not necessarily independent. Alliances and allegiances have been shown to form between gangs that share a common enemy, rival or exhibit a similar gangrelated motive. These alliances are responsible for how gangs respond to conflict, shaping retaliatory patterns of conflicts that may not have been there otherwise (see Bouchard \& Hashimi, 2017; Morselli, Tanguay \& Labalette, 2009; Papachristos et al., 2013). In extreme cases, it may even create a polarized state whereby participants who otherwise would not have been involved in the conflict, or those located on the periphery of the network, may be inclined to choose a side (Morselli et al., 2009).

Relatedly, other studies emphasize that rivalries and alliances are not mutually exclusive categories. For instance, in Montreal, Canada, focus group interviews with 20 gang members belonging to 15 different gangs found that many gang members count their friends, even among their enemies; reporting instances of conflict between members of allied gangs (Descormiers \& Morselli, 2011). Similarly, in Newark, New Jersey, McGloin (2005) found that gang members did not display a homogenous set of allegiances or "gang networks" per so, rather they operated in a series of loosely knit cliques, maintaining associations with 
individuals outside of their "explicit named sets" and members of other gangs (p. 619). This perspective underlies the main demonstration of Morselli's (2009) examination of drug distribution networks, namely that the modal form of criminal entities are ephemeral groups, where collaborations develop between groups opportunistically, to facilitate the commission of crimes and increase profitability (also see Bouchard \& Morselli, 2014).

\section{CONCLUSION}

In many ways, network studies of criminal group dynamics are just getting started. This chapter provides an overview of prior research aimed at integrating group dynamics and network methods but also points to future directions for expanding such efforts. Here, we review three promising areas for moving the area forward.

A Hybrid Approach to Group Dynamics. The bulk of research on criminal group dynamics considers either a group's internal connectivity (i.e., intra-group), or external connectivity (i.e., inter-group), but rarely merges the two. Both perspectives can create important shortcoming in our understanding of group dynamics; groups are considered independent entities, in the former, or as unitary actors lacking variation in their structural features, in the latter. Yet, from the earliest studies of criminal groups we know this not to be the case. Early theories emphasized that the main source of criminal groups' internal cohesion was due to this "group effect" whereby conflicts sustained with other groups increased within-group ties. Conversely, a group's cohesion has been viewed to be threatened by alliance structures that may pull members to other groups. Indeed, a hybrid approach looking at both a group's internal and external network structure may help explain discrepancies in whether a group elects to engage, or not engage in violence, with scholars emphasizing that a group's cohesiveness and solidarity moderates whether inter-group violence escalates or is deterred (see Gould, 2003; Morselli et al., 2008).

Advances in network modeling suggest there is much to be gained from looking at the intersection of these categories. For instance, Shi et al. (2017) demonstrated that a group's ability to persist depended on bridging these two structures, maintaining cohesiveness to retain members, but also creating ties to other organizations to facilitate recruitment (also see Vedres \& Stark, 2010). Drawing from this literature, Ouellet, Charette, and Bouchard (2019) examined the network dynamics of criminal group persistence with an explicit focus on a group's internal and external connectivity. Results showed that groups at different stages in their evolution required distinct network structures to survive. More established groups, with high levels of membership, profited from adopting closed structures to maintain their existing 
position. Whereas, smaller groups, in their early stages of formation, benefited from more versatile structures, opening up to outside associates to expand their access to illicit opportunities. Importantly it was the balance between how a group structured its internal- and external- connectivity which shaped how the group was able to persist over time.

Beyond Delinquency. Another important direction would be to move research on criminal groups beyond delinquency. Even among the most delinquent groups, only a fraction of social activities is spent in the commission of the actual criminal act. Similarly, many of the individuals who may be considered members of a criminal group, may or may not participate in criminal incidents. Changes in both the degree to which a group engages in delinquent behavior, as well as the number of group members who engage in the delinquency may be rooted in other social processes. A focus purely on the delinquent aspects of a group may cloud the more peripheral, but equally important factors that bring together groups, allowing them to forge bonds, and eventually shift into collective actions. For instance, Ouellet and Bouchard's (2018) study of a domestic terrorist organization demonstrated that only a minority of the participants interacting with the group were charged for a crime. Yet, it was the majority who had an impact on the group's evolution. The non-criminal affiliates highlighted variation in the group's structural evolution, and this was related to key turning points in the group's trajectory, including transitions into violence. Network methods provide a means to look beyond delinquent acts and shed attention on the factors that allow groups to emerge and evolve (see Bright et al., 2018; Fitzhugh \& Butts, 2018), and the non-delinquent actors that bring together their delinquent counterparts (Morselli, 2009). These insights could assist in explaining a host of group-level outcomes, including the distribution of criminal groups, their resiliency to interdictions, and changes in group activity over time.

Cross-level Analysis. Network methods are not just an opportunity for advancing our understanding of collective trajectories. More importantly it is also a path for bridging the divide between how individual- and group-level pathways intersect (see Matsueda, 2017). Although the focus of this chapter was on the group-level dynamics associated with crime, it also advances an individual-level research agenda that suggests individual-level variation can only be understood within the context of a group's overall trajectory (see Tremblay et al., 1989). From this perspective, we view individual- and group-level research as naturally compatible fields as inquiry. In fact, one of the strengths of social network analysis is to seamlessly move between different levels of analysis, while keeping them under the same framework. Important work has been done on investigating how group membership structures an individual's offending pathway. However, group membership is often designated as a 
static or binary variable, creating binary cleavages between individuals who belong to a group, and those who do not. Here, we propose nesting individuals within these groups, and distinguishing between different types of groups. For instance, individuals who belong to a highly cohesive gangs may have distinct offending pathways, as compared to individuals who belong to more decentralized, opportunistic entities. The same could be said for individuals who join a gang as it is just forming, versus individuals who join a gang after it has been established and is a staple of a community or inter-group structure. This perspective is consistent with a long line of research that consider offending pathways as structured by opportunities embedded in peer networks (e.g., Conway \& McCord, 2002; McGloin \& Piquero, 2010). And the basic premise underlying Tremblay et al.'s (1989) work on the collective trajectories of organized crime groups.

Notably, cross-level analysis disentangles social interaction effects by representing network dependencies in statistical models. Analytical approaches such as stochastic actororiented models help transition from the macro to the micro level by teasing exogenous (individual level effects), endogenous (structural network effects) from non-effects, longitudinally (Snijders, 2011). Alternatively, analysis of multilevel data with statistical techniques such as hierarchal linear modeling, incorporates effects at various hierarchical levels, modeling cross-level interactions while controlling for their shared variance (Bryk \& Raudenbush, 1992). When supplemented with community detection techniques, statistical models used to deal with complex network dependencies pave the way forward to generate statistical inference, causality, and spillover effects. 


\section{REFERENCES}

Airoldi, E. M., Blei, D. M., Fienberg, S. E., \& Xing, E. P. (2008). Mixed membership stochastic blockmodels. Journal of Machine Learning Research, 9, 1981-2014.

Baker, W. E., \& Faulkner, R. R. (1993). The social organization of conspiracy: Illegal networks in the heavy electrical equipment industry. American Sociological Review, 58(6), 837-867.

Block, A. A. (1979). The snowman cometh: Coke in progressive New York. Criminology, 17(1), 75-99.

Block, A. (1983). East side, west side: Organizing crime in New York, 1930-1950. New Brunswick, U.S.A: Transaction Books.

Blondel, V. D., Guillaume, J.-L., Lambiotte, R., \& Lefebvre, E. (2008). Fast unfolding of communities in large networks. Journal of Statistical Mechanisms: Theory and Experiment, 10, P10008.

Bouchard, M., \& Hashimi, S. (2017). When is a "war" a "wave?": Two approaches for the detection of waves in gang homicides. Canadian Journal of Criminology and Criminal Justice, 59(2), 198-226.

Bouchard, M., \& Malm, A. (2016). Social network analysis and its contribution to research on crime and criminal justice. Oxford Handbooks Online. Retrieved from http://www.oxfordhandbooks.com/view/10.1093/oxfordhb/9780199935383.001.0001/ oxfordhb-9780199935383-e-21

Bouchard, M., \& Morselli, C. (2014). Opportunistic structures of organized crime. In L. Paoli The Oxford Handbook of Organized Crime (pp. 288-302). Oxford: Oxford University Press.

Bright, D., Koskinen, J., \& Malm, A. (2018). Illicit network dynamics: The formation and evolution of a drug trafficking network. Journal of Quantitative Criminology. Online First.

Bryk, A.S., \& Raudenbush, S. W. (1992). Hierarchical linear models: Applications and data analysis methods. Newbury Park, CA: Sage Publications.

Bursik, R. J. (1998). Social disorganization and theories of crime and delinquency: Problems and prospects. Criminology, 26(4), 519-551.

Calderoni, F., Brunetto, D., \& Piccardi, C. (2017). Communities in criminal networks: A case study. Social Networks, 48, 116-125.

Campana, P. (2011). Eavesdropping on the mob: The functional diversification of Mafia activities across territories. European Journal of Criminology, 8(3), 213-228.

Campana, P. (2015). The structure of human trafficking: Lifting the bonnet on a Nigerian transnational network. The British Journal of Criminology, 56(1), 68-86. 
Campana, P. (2016). Explaining criminal networks: Strategies and potential pitfalls. Methodological Innovations, 9, 1-10.

Campana, P., \& Varese, F. (2012). Listening to the wire: Criteria and techniques for the quantitative analysis of phone intercepts. Trends in Organized Crime, 15(1), 13-30.

Carrington, P. J. (2002). Group crime in Canada. Canadian Journal of Criminology, 44(3), 277-315.

Carrington, P. J. (2011). Crime and social network analysis. In J. Scott \& P. J. Carrington The SAGE Handbook of Social Network Analysis (pp. 236-255). Thousand Oaks, CA: Sage Publications Ltd.

Carrington, P. J., Scott, J., \& Wasserman, S. (2005). Models and methods in social network analysis. Cambridge: Cambridge University Press.

Castells, M. (2010). Globalisation, networking, urbanisation: Reflections on the spatial dynamics of the information age. Urban Studies, 47(13), 2737-2745.

Chase, I. V. (1980). Social process and hierarchy formation in small groups: A comparative perspective. American Sociological Review, 45(6), 905-924.

Clauset, A., Newman, M. E. J., \& Moore, C. (2004). Finding community structure in very large networks. Physical Review, 70, 0661111-1-6.

Collins, R. (1988). Theoretical sociology. New York: Harcourt Brace Jovanovich.

Conway, K. P., \& McCord, J. (2002). A longitudinal examination of the relation between cooffending with violent accomplices and violent crime. Aggressive Behavior, 28(2), 97-108.

Crossley, N., Edwards, G., Harries, E., \& Stevenson, R. (2012). Covert social movements and the secrecy-efficiency trade off: The case of the UK suffragettes (1906-1914). Social Networks, 34, 634-644.

Decker, S. H. (1996). Collective and normative features of gang violence. Justice Quarterly, 13(2), 243-264.

Decker, S. H., \& Curry, D. G. (2002). Gangs, gang homicides, and gang loyalty: Organized crimes or disorganized criminals. Journal of Criminal Justice, 30, 343-352.

Descormiers, K., \& Morselli, C. (2011). Alliances, conflicts, and contradictions in Montreal's street gang landscape. International Criminal Justice Review, 21(3), 297-314.

Duxbury, S. W., \& Haynie, D. L. (2018). The network structure of opioid distribution on a darknet cryptomarket. Journal of Quantitative Criminology, 34, 921-941. 
Eagle, N., Pentland, A. S., \& Lazer, D. (2009). Inferring friendship network structure by using mobile phone data. Proceedings of the National Academy of Sciences, 106(36), 15274-15278.

Everett, M. G., \& Borgatti, S. P. (1998) Analyzing clique overlap. Connections, 21(1), 49-61.

Faust, K., \& Tita, G. E. (2019). Social networks and crime: Pitfalls and promises for advancing the field. Annual Review of Criminology, 2, 99-122.

Fitzhugh, S. M., \& Butts, C. T. (2018). Patterns of co-membership: Techniques for identifying subgraph composition. Social Networks, 55, 1-10.

Fortunato, S., Barthélemy, M. (2007). Resolution limit in community detection. Proceedings of the National Academy of Sciences, 104(1), 36-41.

Gallupe, O. (2016). Network analysis. In B. M. Huebner \& T. S. Bynum The Handbook of Measurement Issues in Criminology and Criminal Justice (pp. 555-575). Oxford: John Wiley.

Gallupe, O., Gravel, J. (2018). Social network position of gang members in schools: Implications for recruitment and gang prevention. Justice Quarterly, 35(3), 505-525.

Girvan, M., \& Newman, M. E. J. (2002). Community structure in social and biological networks. Proceedings of the National Academy of Sciences, 99(12), 7821-7826.

Good, B. H., de Montjoye, Y.-A., \& Clauset, A. (2010). Performance of modularity maximization in practical contexts. Physical Review E, 81, 046106.

Gould, R. V. (2003). Collison of wills: How ambiguity about social rank breeds conflict. Chicago, IL: University of Chicago Press.

Gravel, J., \& Tita, G. E. (2017). Network perspectives on crime. In Oxford Research Encyclopedia of Criminology (1-42). Oxford University Press.

Harris, K. M., Halpern, C. T., Whitsel, E., Hussey, J., Tabor, J., Entzel, P., \& Udry, J. R. (2009). The National Longitudinal Study of Adolescent to Adult Health: Research Design. Retrieved from http://www.cpc.unc.edu/projects/addhealth/design. Accessed on January 30, 2019.

Hashimi, S., \& Bouchard, M. (2017). On to the next one? Using social network data to inform police target prioritization. Policing: An International Journal of Police Strategies \& Management, 40(4), 768-782.

Hashimi, S., Bouchard, M., Morselli, C., \& Ouellet, M. (2017). A method to detect criminal organizations from police data. Methodological Innovations, 9, 1-14.

Haynie, D. L. (2001). Delinquent peers revisited: Does network structure matter? American Journal of Sociology, 106(4), 1013-1057. 
Haynie, D. L., \& Kreager, D. A. (2013). Peer networks and crime. In F. T. Cullen \& P. Wilcox The Oxford Handbook of Criminological Theory (pp. 257-273). New York, NY: Oxford University Press.

Heckathorn, D. D. (1997). Respondent-driven sampling: A new approach to the study of hidden populations. Social Problems, 44(2), 174-199.

Heckathorn, D. D., \& Cameron, C. J. (2017). Network sampling: From snowball and multiplicity to respondent-driven sampling. Annual Review of Sociology, 43, 101-119.

Hughes, L. A. (2013). Group cohesiveness, gang membership prestige, and delinquency and violence in Chicago, 1959-1962. Criminology, 51, 795-832.

Jansyn, L. R. (1966). Solidarity and delinquency in a street corner group. American Sociological Review, 31(5), 600-614.

Klein, M. W. (1969). Gang cohesiveness, delinquency, and a street-work program. Journal of Research in Crime and Delinquency, 6(2), 135-166.

Klein, M. W. (1971). Street gangs and street workers. Englewood Cliffs, NJ: Prentice-Hall.

Klein, M. W., \& Crawford, L. Y. (1967). Groups, gangs, and cohesiveness. Journal of Research in Crime and Delinquency, 4(1), 63-75.

Kreager, D. A., Rulison, K., \& Moody, J. (2011). Delinquency and the structure of adolescent peer groups. Criminology, 49(1), 95-127.

Lane, J. (2019). The digital street: Adolescence, technology, and community in the inner city. New York: Oxford University Press.

Lantz, B., \& Hutchison, R. (2015). Co-offender ties and the criminal career: The relationship between co-offender group structure and the individual offender. Journal of Research in Crime and Delinquency, 52(5), 658-690.

Lewin, K. (1948). Resolving social conflict: Selected papers on group dynamics. New York, NY: Harper \& Row Publishers, Inc.

Malm A., \& Bichler, G. (2011). Networks of collaborating criminals: Assessing the structural vulnerability of drug markets. Journal of Research in Crime and Delinquency, 48(2), 271-297.

Malm, A., Bichler, G., \& Nash, R. (2011). Co-offending between criminal enterprise groups. Global Crime, 12, 112-128.

Matsueda, R. L. (2017). Toward an analytical criminology: The micro-macro problem, causal mechanisms, and public policy. Criminology, 55(3), 493-519.

McGloin, J. M. (2005). Policy and intervention considerations of a network analysis of street gangs. Criminology \& Public Policy, 4(3), 607-636. 
McGloin, J. M., \& Kirk, D. S. (2010a). An overview of social network analysis. Journal of Criminal Justice Education, 21(2), 169-181.

McGloin, J. M., \& Kirk, D. S. (2010b). Social network analysis. In A. Piquero \& D. Weisburd Handbook of Quantitative Criminology (pp. 209-224). New York, NY: Springer.

McGloin, J. M., \& Piquero, A. (2010). On the relationship between co-offending network redundancy and offending versatility. Journal of Research in Crime and Delinquency, 47(1), 63-90.

Miller, J. (2001). One of the guys: Girls, gangs, and gender. New York, NY: Oxford University Press.

Miller, E. (2012). Patterns of onset and decline among terrorist organizations. Journal of Quantitative Criminology, 28(1), 77-101.

Miller, W. B. (1957). The impact of a community group work program on delinquent corner groups. Social Service Review, 31(4), 309-406.

Miller, W. B. (1958). Lower class culture as a generating milieu of gang delinquency. Journal of Social Issues, 23, 5-19.

Miller, W. B. (1962). The impact of a "total-community" delinquency control project. Social Problems, 10, 168-191.

Morselli, C. (2009). Inside criminal networks. New York: Springer.

Morselli, C., Giguère, C., \& Petit, K. (2007). The efficiency/security trade-off in criminal networks. Social Networks, 29(1), 143-153.

Morselli, C., Tanguay, D., \& Labalette, A.-M. (2008). Criminal conflicts and collective violence: Biker-related account settlements in Quebec, 1994-2001. In D. Siegel \& H. Nelen Organized Crime: Culture, Markets and Policies (pp. 145-164). Springer.

Morselli, C., \& Tremblay, P. (2004). Criminal achievement, offender networks, and the benefits of low self-control. Criminology, 42(3), 773-804.

Morselli, C., Tremblay, P., \& McCarthy, B. (2006). Mentors and criminal achievement. Criminology, 44(1), 17-43.

Mucha, P. J., Richardson, T., Macon, K., Porter, M. A., \& Onnela, J.-P. (2010). Community structure in time-dependent, multiscale, and multiplex networks. Science, 328, 876878.

Newman, M. E. J. (2006). Modularity and community structure in networks. Proceedings of the National Academy of Sciences, 103(23), 8577-8582.

Newman, M. E. J. (2018). Networks, $2^{\text {nd }}$ Ed. Oxford, UK: Oxford University Press. 
Newman, M. E. J., \& Girvan, M. (2004). Finding and evaluating community structure in networks. Physical Review E, 69, 026113.

Ouellet, M., \& Bouchard, M. (2018). The 40 members of the Toronto 18: Group boundaries and the analysis of illicit networks. Deviant Behavior, 39(11), 1467-1482.

Ouellet, M., Bouchard, M., \& Charette, Y. (2019). One gang dies, another gains? The network dynamics of criminal group persistence. Criminology, Online First.

Palla, G., Barabási, A., \& Vicsek, T. (2007). Quantifying social group evolution. Nature, 446, 664-667.

Palla, G., Derényi, I., Farkas, I, Vicsek, T. (2005). Uncovering the overlapping community structure of complex networks in nature and society. Nature, 435,814-818.

Papachristos, A. V. (2006). Social network analysis and gang research: Theory and methods. In J. F. Short \& L. A. Hughes Studying Youth Gangs (pp. 99-116). Lanham, MD: Altamira.

Papachristos, A. V. (2009). Murder by structure: Dominance relations and the social structure of gang homicide. American Journal of Sociology, 115(1), 74-128.

Papachristos, A. V. (2011). The coming of a networked criminology. In J. MacDonald Advances in Criminological Theory (pp. 101-140). New Brunswick, NJ: Transaction Publishers.

Papachristos, A. V. (2013). The importance of cohesion for gang research, policy, and practice. Criminology \& Public Policy, 12(1), 49-58.

Papachristos, A. V., Hureau, D. M., \& Braga, A. A. (2013). The corner and the crew: The influence of geography and social networks on gang violence. American Sociological Review, 78(3), 417-447.

Paoli, L. (2002). The paradoxes of organized crime. Crime, Law and Social Change, 37(1), 51-97.

Patton, D. U., Lane, J., Leonard, P., MacBeth, J. \& Smith Lee, J. R. (2017). Gang violence on the digital street: Case study of a South Side Chicago gang member's Twitter communication. New Media \& Society, 19(7), 1000-1018.

Pyrooz, D. C., \& Mitchell, M. M. (2015). Little gang research, big gang research. In S. H. Decker \& D. C. Pyrooz The Handbook of Gangs (pp. 28-55). West Sussex, UK: John Wiley \& Sons, Inc.

Radil, S. M., Flint, C., \& Tita, G. E. (2010). Spatializing social networks: Using social network analysis to investigate geographies of gang rivalry, territoriality and violence in Los Angeles, Annals of the Association of American Geographers, 100(2), 307326. 
Sanchez-Jankowski, M. (1991). Islands in the street: Gangs and American urban society. Los Angeles, CA: University of California Press.

Sarnecki, J. (2001). Delinquent networks: Youth co-offending in Stockholm. Cambridge, U.K.: Cambridge University Press.

Schaefer, D. R., Bouchard, M., Young, J. T. N., \& Kreager, D. A. (2017). Friends in locked places: An investigation of prison inmate network structure. Social Networks, 51, 88103.

Schmidt, L. A. (2012). Social Networking and the Fourth Amendment: Location Tracking on Facebook, Twitter, and Foursquare. Cornell Journal of Law and Public Policy, 22(2), $515-536$.

Shi, Y., Fedor A. D., Genkin, M., \& Brashears, M. E. (2017). A member saved is a member earned? The recruitment-retention trade-off and organizational strategies for membership growth. American Sociological Review, 82(2), 407-434.

Shirkhorshidi, A. S., Aghabozorgi, S., \& Wah, T. Y. (2015). A comparison study on similarity and dissimilarity measures in clustering continuous data. PloS one. Retrieved from https://journals.plos.org/plosone/article?id=10.1371/journal.pone.0144059. Accessed January 30, 2019.

Short, J. F. (1974). Youth, gangs and society: Micro- and macrosociological Processes. The Sociological Quarterly, 15(1), 3-19.

Short J. F. (1998). The level of explanation problem revisited. Criminology, 36, 3-36.

Short, J. F., \& Strodtbeck, F. L. (1965). Group process and gang delinquency. Chicago: University of Chicago Press.

Sierra-Arévalo, M., \& Papachristos, A. V. (2015). Social network analysis and gangs. In S. H. Decker \& D. C. Pyrooz The Handbook of Gangs (pp. 157-177). West Sussex, UK: John Wiley \& Sons, Inc.

Simmel, G. (1955). The web of group-affiliation. New York: Free Press.

Snijders, T. A. (2011). Statistical models for social networks. Annual Review of Sociology, 37, 131-153.

Stevenson, R., \& Crossley, N. (2014). Change in covert social movement networks: The 'inner circle' of the Provisional Irish Republican Army. Social Movement Studies, 13(1), 70-91.

Sugie, N. F. (2018). Utilizing smartphones to study disadvantaged and hard-to-reach groups. Sociological Methods \& Research, 47(3), 458-491.

Suttles, G. D. (1968). The social order of the slum: Ethnicity and territory in the inner city. Chicago, IL: University of Chicago Press. 
Thornberry, T., Krohn, M., Lizotte, A., \& Chard-Wierschem, D. (1993). The Role of Juvenile Gangs in Facilitating Delinquent Behavior. Journal of Research in Crime and Delinquency, 30(1), 55-87.

Thrasher, F. M. (1927). The gang: A study of 1,313 gangs in Chicago. Chicago, IL: University of Chicago Press.

Tita, G. E., \& Radil, S. M. (2011). Spatializing the social networks of gangs to explore patterns of violence. Journal of Quantitative Criminology, 27(4), 521-545.

van Gennip, Y., Hu, H., Hunter, B., Porter, M. A. (2012). Geosocial graph-based community detection. IEEE $12^{\text {th }}$ International Conference on Data Mining Workshops. Retrieved from https://ieeexplore.ieee.org/abstract/document/6406515/authors. Accessed January 30, 2019.

Vedres, B., \& Stark, D. (2010). Structural folds: Generative disruption in overlapping groups. American Journal of Sociology, 115(4), 1150-1190.

Vigil, J. D. (1988). Barrio gangs: Street life and identity in Southern California. Austin: University of Texas Press. 


\section{${ }^{4}$ Endnotes}

${ }^{1}$ Evidence of this increase can be observed across ample, high quality reviews of applications of network analysis to the study of criminal phenomena, including: Bouchard \& Malm (2016); Campana (2016); Carrington (2011); Faust \& Tita (2019); Gallupe (2016); Gravel \& Tita (2017); Haynie \& Kreager (2013); McGloin \& Kirk (2010a; 2010b); Papachristos (2006; 2011); and Sierra-Arévalo \& Papachristos (2015).

${ }^{2}$ The authors also estimated models where cohesion was operationalized as the mean number of friendship nominations received; the proportion of intra-gang nominations (i.e., density) with a control for size; and the maximum k-core (based on undirected ties). All substantive results remained the same.

${ }^{3}$ To identify the presence of gangs: (a) high in status, perpetrated violence against other gangs, but were not the targets of violence; (b) low in status, did not perpetrate violence, but were the targets of violence; and (c) gangs in the middle of the hierarchy who were both perpetrators and targets of gang violence. 